\title{
ECG Recording Quality
}

National Cancer Institute

\section{Source}

National Cancer Institute. ECG Recording Quality. NCI Thesaurus. Code C114120.

A finding pertaining to the quality of an ECG recording. 